\title{
Balloon kyphoplasty in the treatment of metastatic disease of the spine: a 2-year prospective evaluation
}

\author{
R. Pflugmacher $\cdot$ R. Taylor $\cdot$ A. Agarwal $\cdot$ I. Melcher $\cdot$ \\ A. Disch · N. P. Haas · C. Klostermann
}

Received: 24 February 2008 / Revised: 11 May 2008 / Accepted: 25 May 2008 / Published online: 17 June 2008

(C) The Author(s) 2008

\begin{abstract}
There is currently little data on the longer term efficacy and safety of balloon kyphoplasty (BKP) in patients with metastatic vertebral compression fractures (VCFs). To prospectively assess the long-term efficacy and safety of BKP in treating thoracic and lumbar spinal metastatic fractures that result in pain or instability. Sixtyfive patients (37 men, mean age: 66 years) underwent 99 BKP procedures. Patient-related outcomes of pain visual analogue scale (VAS) and Oswestry Disability Index were assessed pre- and post-operatively and after 3, 6, 12 and 24 months. Correction of vertebral height and kyphotic deformity were assessed by radiographic measurements. Mean pain VAS and Oswestry Disability Index significantly improved from pre- to post-treatment $(P<0.0001)$, this improvement being sustained up to 24-month follow up. A gain in height restoration and a reduction of the post-
\end{abstract}

R. Pflugmacher $(\bowtie) \cdot$ I. Melcher · A. Disch · N. P. Haas Centrum für Muskuloskeletale Chirurgie, Klinik Für Orthopädie, Klinik für Unfall- und Wiederherstellungschirurgie,

Charité - Universitätsmedizin Berlin,

Campus Virchow-Klinikum, Augustenburgerplatz 1,

13353 Berlin, Germany

e-mail: robert.pflugmacher@ charite.de

R. Taylor

Peninsula Medical School, Universities of Exeter and Plymouth, Exeter, UK

\author{
A. Agarwal \\ Medway Maritime Hospital, University of London \\ Associated Teaching Hospital, Windmill Road, \\ Gillingham Kent ME7 5NY, UK \\ C. Klostermann \\ Klinikum Lippe-Lemgo, Klinik für Unfall- und \\ Wiederherstellungschirurgie, Rintelner Str. 85, \\ 32657 Lemgo, Germany
}

operative kyphotic angle were seen post-operatively and at 3 months although these radiographic outcomes returned to pre-operative levels at 12 months. BKP was associated with a rate of cement leakage and incidence vertebral fracture of 12 and $8 \%$, respectively. No symptomatic cement leaks or serious adverse events were seen during the 24 months of follow up. BKP is a minimally invasive procedure that provides immediate and long-term pain relief and improvement in functional ability in selected patients with metastatic VCFs. The procedure appears to have good long-term safety.

Keywords Spine - Metastasis - Pathological fractures · Osteolytic lesions $\cdot$ Balloon kyphoplasty

\section{Introduction}

Vertebral deformities or vertebral compression fractures (VCFs) are frequently seen as a consequence of osteolytic or metastatic disease $[13,15]$. VCFs constitute a major health care problem, not only because of the high incidence of these lesions but also due to their direct and indirect negative consequences for patient health-related quality of life and the costs to the health care system [1, 3, 4, 13, 18, 22].

Balloon kyphoplasty (BKP) is a minimally invasive procedure that stablises the vertebral fracture and also provides the opportunity to restore vertebral height and reduce spinal kyphosis [14, 21]. Kyphosis of the spine may compromise the biomechanics of the spine, which in turn predisposes to increased risk of further fractures in the adjacent vertebrae $[10,19]$. A number of reviews have recently shown BKP to be efficacious, providing rapid pain relief, reduced need for pain medication, improvement of functional disability and enhanced health-related quality of 
life $[2,9,12,23]$. Compared to non-surgical conventional medical therapy, BKP reduces subsequent adjacent fractures $[2,9,12,23]$ and has a lower risk of cement leakage when compared to vertebroplasty [9, 12, 23].

Few studies to date have reported on the outcomes of BKP in the treatment of metastatic lesions of the spine [5, 7, 8, 11, 14, 16, 17, 24]. A recent systematic review identified that only about $2 \%$ of BKP outcome data had been collected in patients with metastatic VCFs. Furthermore, these data were frequently collected in small number metastatic lesions in mixed case series where osteoporosis was the dominant indication with short-term follow up [23]. Here we report the short-term and longer term efficacy and safety outcomes in a cohort of patients with metastatic fractures in thoracic and lumbar spine treated with BKP.

\section{Materials and methods}

\section{Patient selection}

Between May 2001 and November 2004, 65 patients underwent BKP. Patients were included in this prospective series if they have experienced: severe back pain refractory or danger of further vertebral deformation and osteolytic lesions of the spine caused by secondary cancer of the prostate, cervix, rectum, lung, ovaries, pancreas, breast, skin and gastrointestinal system. All patients pre-operatively underwent a radiograph of the spine and a CT scan of the fractured vertebral body to evaluate the posterior wall. Furthermore, all patients underwent an MRI scan of the spine to detect further asymptomatic lesions (Fig. 1). The diagnosis was established by the patient history and radiographic evaluation. The diagnosis of bone metastasis had been secured on bone aspirate and trephine biopsy. BKP was not performed in case of a severe spinal stenosis with infiltration of the posterior wall or if the patient had any neurological deficit according to the vertebra which should be treated. All surgical procedures were done with informed consent from the patients.

Implants and surgical technique

BKP was performed under general anaesthesia using the $\mathrm{KyphX}^{\circledR}$ System (Kyphon Inc., Sunnyvale, California). The surgical technique for the procedure has been described by Lieberman et al. [14]. A bilateral approach was chosen to insert working cannulas into the posterior part of the vertebral body. Biplanar fluoroscopy was used to insert the tools and control the procedure. With reaming tools, two working channels were created and the KyphX Xpander $^{\circledR}$ balloons were inserted. The KyphX Xpander ${ }^{\circledR}$ balloons are available in lengths of 10,15 and $20 \mathrm{~mm}$. The KyphX Xpander ${ }^{\circledR}$ balloons should ideally be centered between the endplates in the anterior two-thirds of the vertebral body. Their placement can be controlled by two radiopaque markers at the ends of the balloon. Once inserted, the KyphX Xpander ${ }^{\circledR}$ balloons were inflated using visual, volume and pressure control to create a cavity. Inflation was stopped when one of the endpoints of inflation was reached: the pressure raised over $400 \mathrm{psi}$, the KyphX Xpander ${ }^{\circledR}$ balloon contacted the cortical wall of the vertebra or the maximal inflation volume of the balloon was reached. The balloons were then deflated and removed. The mean balloon inflation volume was $4.1 \mathrm{ml}$ (range 1.3$5.5 \mathrm{ml}$ ). The $\mathrm{Kyph}^{\circledR}$ Bone Filler Device, which was filled before with $1.5 \mathrm{ml}$ of polymethylmethacrylate (PMMA), was then advanced through the working cannula towards the anterior part of the cavity and cement was slowly extruded by a stainless steel stylet, acting as a plunger. When the amount of cement from $1 \mathrm{KyphX}^{\circledR}$ Bone Filler Device was delivered in the cavity, the first was removed and the next $\mathrm{Kyph}^{\circledR}$ Bone Filler Device was advanced through the working cannula. This step was repeated till a complete fill of the cavity was obtained. The same procedure was repeated through the other working cannula at the contra-lateral pedicle. Filling of the cavity with highly viscous PMMA was performed under continuous fluoroscopic control.

All patients were treated with the same post-operative protocol and were mobilised one day post-operatively. Radiographic controls were performed 1-3 days after operation (Fig. 1). Analgesia was adapted to the severity of the back pain: no opiate analgesia was necessary postoperatively. All patients received oncologic treatment (radiation therapy and/or chemotherapy) 2-4 weeks postintervention.

\section{Outcomes}

Outcomes were assessed prior to surgery, post-operatively and at 3, 6, 12 and 24 months.

\section{Patient-related measures}

Back pain was assessed using with a ten-point visual analogue scale (VAS) where a score of zero indicated 'no pain' and a score of 10 indicated 'severe pain' (10). Functional capacity was assessed using the oswestry disability instrument (ODI) [6].

\section{Radiographic parameters}

Plain digital radiographs were performed before and 3 days after surgery, at 3, 6, 12 and 24 months follow-up. 

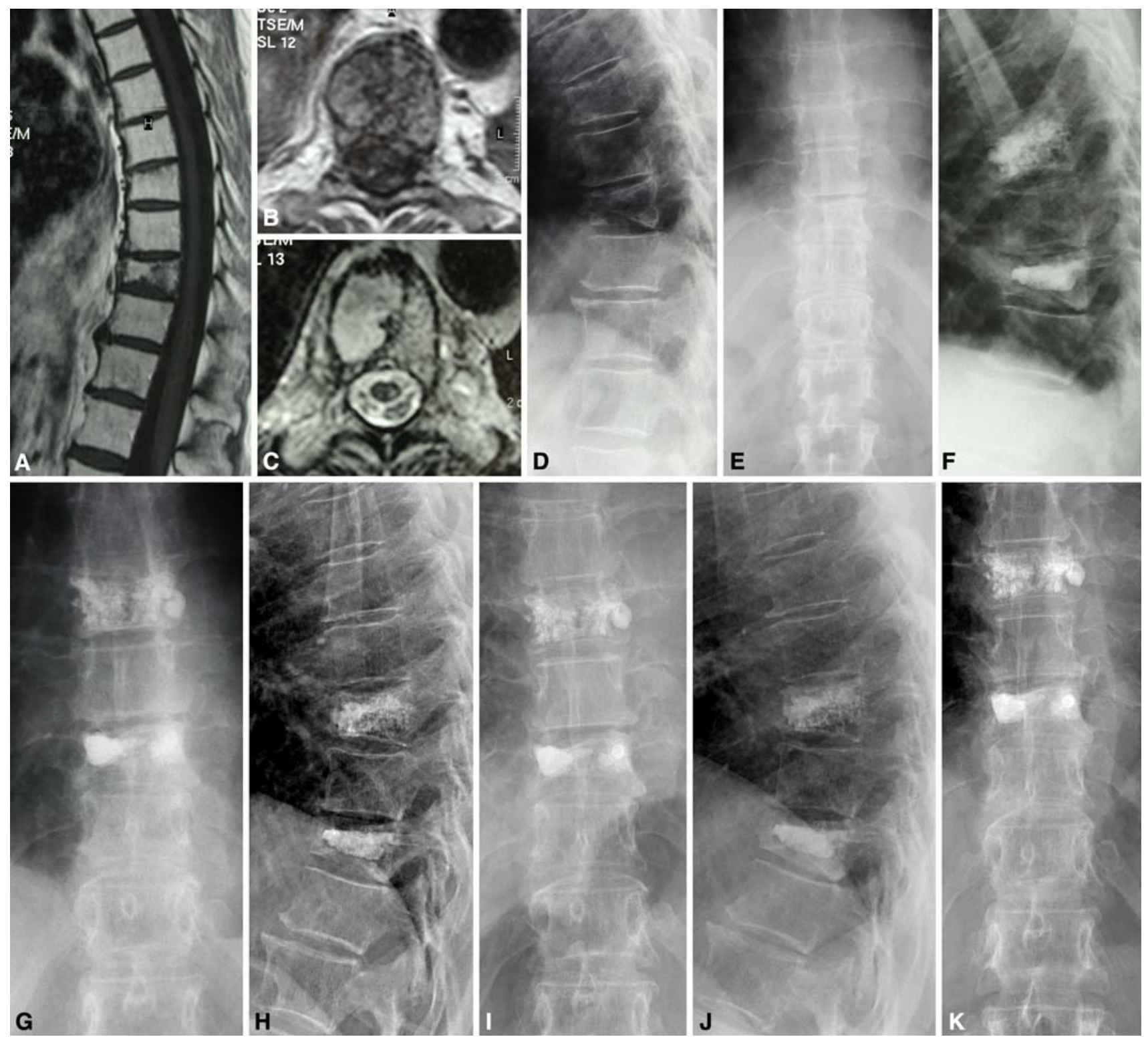

Fig. 1 Pre-operatively and radiograph pre-, post-operatively, and 2 years post-operatively of a 82-year-old patient with a metastatic ovarial carcinoma treated with Balloon-kyphoplasty in level T 11 and

Additionally, radiographic evaluation including CT-scans with sagittal 2-D reconstruction as well as MRI was performed before surgery. The CT scan was performed in a multi detector spiral CT 16 row (Light Speed Pro 16, GE, Milwaukee, Wisc., USA). The slice thickness was $2.5 \mathrm{~mm}$ with a bone algorithm. MRI (Signa 1.5 T, GE, Milwaukee, Wisc., USA) scanning included $\mathrm{T} 1$ and $\mathrm{T} 2$ sequences; $0.2 \mathrm{mg} / \mathrm{kg}$ body weight paramagnetic contrast agent (Magnevist, Schering, Berlin, Germany) was used.

Loss of vertebral body height and degree of kyphosis were measured in lateral radiographs by calliper in the digital system. The anterior and mid-vertebral heights were defined as the distance between the upper and lower
L2. a-c MRI preoperatively. d-e Radiograph preoperatively. f-g Radiograph postoperatively. $\mathbf{h}-\mathbf{i}$ Radiograph 1 year. $\mathbf{j}-\mathbf{k}$ Radiograph 2 years

endplates at the anterior vertebral wall and in the centre of the vertebra, respectively. The normal heights for the anterior vertebral wall and mid-vertebral region were considered as the sum of the measurement of the corresponding heights of the adjacent superior and inferior nearest non-fractured vertebrae divided by two. Two independent assessors evaluated radiometric outcomes.

\section{Adverse events}

All adverse events, including cement leakages were collected. Cement leaks were confirmed by intra-operative fluoroscopy and post-operative radiograph. New fractures 
were assessed in previously unfractured and pre-fractured vertebrae.

\section{Statistical analysis}

All outcomes were reported descriptively at all assessment points. To maximise statistical efficiency, repeated measures analysis of variance (ANOVA) was first used to assess within person differences across the six outcome time points [24]. Where the ANOVA model showed statistical significance $(P \leq 0.05)$, within group $t$ tests were used to compare differences in means across pairs of time points. Differences are expressed as means and 95\% confidence intervals $(95 \% \mathrm{CI})$. All analyses were conducted using Stata v.8.0 (Stata Corp, College Station, Texas).

\section{Results}

A total of 65 consecutive patients meeting the inclusion criteria were included and underwent a total of 99 BKP procedures (see Table 1). Two-year follow up was available on 41 patients. Thirteen patients died before 1-year follow up and another nine patients died from between 12 and 24 months. Two patients had a cardiac arrest all others deaths were cancer related. None of the deaths were procedure related.

\section{Patient-related outcomes}

Balloon Kyphoplasty treated patients exhibited a marked improvement in mean VAS pain (33 vs. $83 \mathrm{~mm}$ ) and mean ODI scores (38 vs. 81) post-operatively (both $P<0.0001$ ) which continued to improve to 3 -months. There was some evidence of a small but not clinically important deterioration of VAS and ODI score from in period from 6 to 24 months follow up (Table 2, Figs. 2, 3).

Table 1 Pre-operative patient characteristics and operative details

\begin{tabular}{ll}
\hline Total patients $N=65$ & $N(\%)$ or mean (SD) \\
\hline Sex, male & $37(57 \%)$ \\
Age, years & $66(9)$ \\
No. of vertebral levels operated on & \\
One level & $37(59 \%)$ \\
Two levels & $23(25 \%)$ \\
Three levels & $4(6 \%)$ \\
Four levels & $1(2 \%)$ \\
Pre-operative pain VAS & $83(15)$ \\
Pre-operative ODI & $81(8)$ \\
\hline
\end{tabular}

Table 2 Pain VAS and ODI scores-preoperative and at follow up

\begin{tabular}{|c|c|c|c|c|}
\hline & \multicolumn{2}{|l|}{ Pain VAS } & \multicolumn{2}{|l|}{ ODI } \\
\hline & $N$ patients & Mean (SD) & $N$ patients & Mean (SD) \\
\hline Pre-operative & 65 & $83(15)$ & 65 & $81(8)$ \\
\hline Post-operative & 65 & $33(9) * * *$ & 65 & $39(7)^{* * *}$ \\
\hline 3-months & 63 & $29(9) * * * \dagger$ & 63 & $33(6) * * *+\dagger$ \\
\hline 6-months & 58 & $29(10)^{*} * * t^{\dagger}$ & 59 & $32(7) * * * \dagger \dagger$ \\
\hline 12-months & 52 & $31(10)^{* * *}$ & 52 & $32(7) * * *+\dagger$ \\
\hline 24-months & 41 & $32(10)^{* * *}$ & 41 & $35(6) * * * \dagger \dagger$ \\
\hline
\end{tabular}

*** $P<0.0001$ compared to pre-operative; ${ }^{\dagger \dagger} P<0.0001$ compared to post-operative; ${ }^{\dagger \dagger} P<0.001$ compared to post-operative

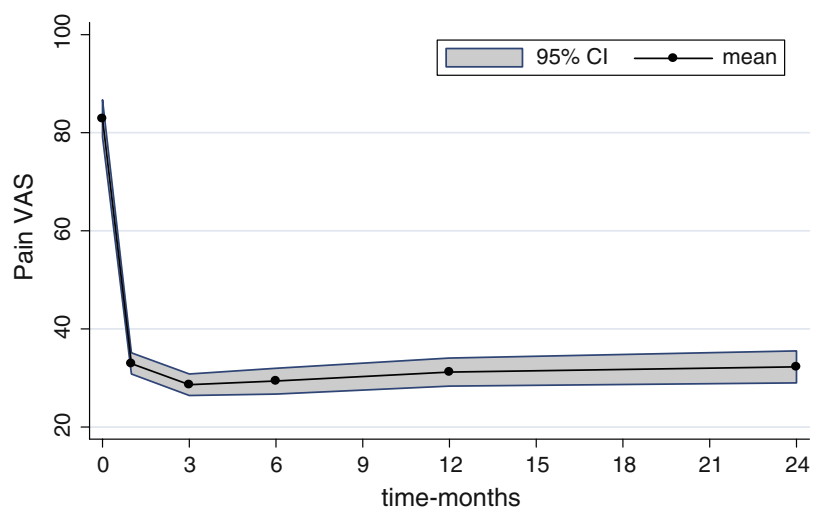

Fig. 2 Pattern of change in pain VAS scores. Time 0: pre-operative; time 3-4 days: post-operative

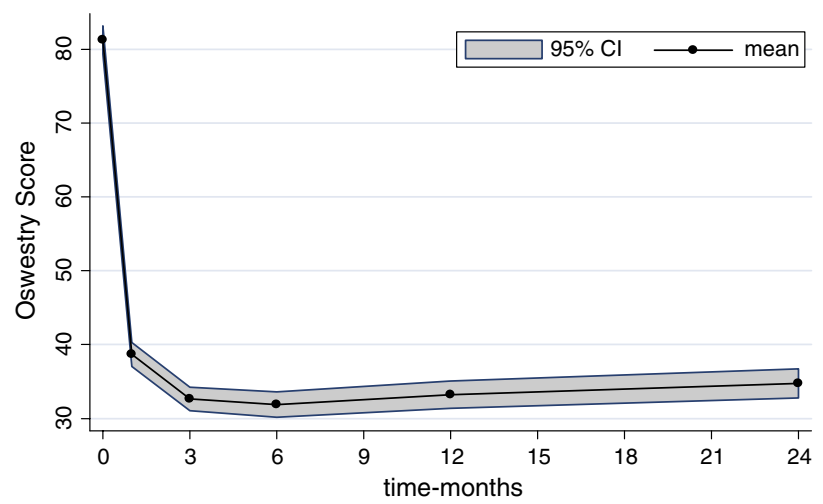

Fig. 3 Pattern of change in ODI scores. Time 0: pre-operative; time 3-4 days: post-operative

Radiographic outcomes

Post-operatively, midline and anterior vertebral body height was significantly increased $(P<0.0001)$ and this change was maintained at 3 months follow up. Over the period of 6-24 months, midline and anterior vertebral height gradually decreased to a pre-operative level (Table 3, Fig. 4, 5). A similar pattern of change was seen in kyphotic angle, i.e. a significant reduction in 
Table 3 Vertebral height and kyphotic angle-pre-operative and at follow up

\begin{tabular}{|c|c|c|c|c|c|c|}
\hline & \multicolumn{2}{|c|}{ Anterior vertebral height (mm) } & \multicolumn{2}{|c|}{ Midline vertebral height (mm) } & \multicolumn{2}{|c|}{ Kyphotic angle $\left(^{\circ}\right)$} \\
\hline & $N$ & Mean (SD) & $N$ & Mean (SD) & $N$ & Mean (SD) \\
\hline Pre-operative & 99 & $23.7(2.4)$ & 98 & $24.5(1.8)$ & 99 & $12.0(2.3)$ \\
\hline Post-operative & 99 & $24.2(2.4)^{* * * *}$ & 98 & $24.8(1.9)^{* *}$ & 98 & $11.1(2.4)^{* * *}$ \\
\hline 3-months & 94 & $24.2(2.5)^{* * *} \mathrm{NS}$ & 92 & $24.8(1.9)^{* \dagger}$ & 94 & $11.5(2.4)^{* *+\dagger}$ \\
\hline 6-months & 83 & $23.9(2.5)^{* *} \mathrm{NS}$ & 81 & $24.6(1.9)^{* \dagger}$ & 83 & $11.8(2.4)^{*+\dagger}$ \\
\hline 12-months & 76 & $23.6(2.4)^{* \dagger}$ & 76 & $24.5(1.9)^{* * \dagger}$ & 76 & $11.8(2.4)^{*+\dagger}$ \\
\hline 24-months & 57 & $23.7(2.3)^{* \dagger}$ & 60 & $24.5(1.9) \mathrm{NS}^{\dagger}$ & 53 & $12.0(3.3) \mathrm{NS}^{\dagger \dagger}$ \\
\hline
\end{tabular}

*** $P<0.0001$ compared to pre-operative; ** $P<0.001$ compared to pre-operative; $* P<0.05$ compared to pre-operative; ${ }^{\dagger \dagger \dagger} P<0.0001$ compared to post-operative; ${ }^{\dagger \dagger} P<0.001$ compared to post-operative; ${ }^{\dagger} P<0.05$ compared to post-operative; NS $P>0.05$ not statistically significant

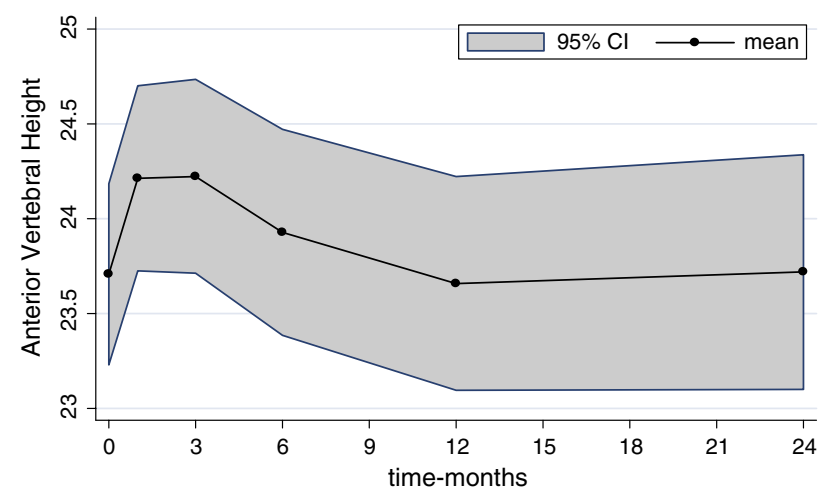

Fig. 4 Pattern of change in anterior vertebral height. Time 0: preoperative; time 3-4 days: post-operative

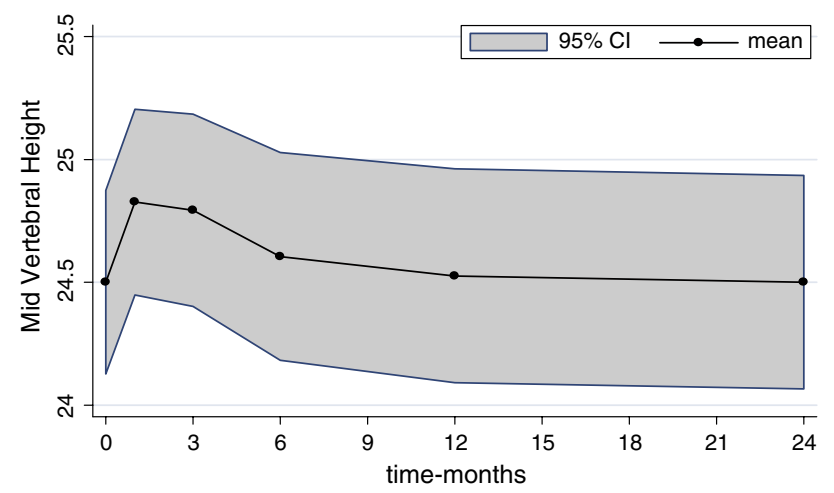

Fig. 5 Pattern of change in midline vertebral height. Time 0: preoperative; time 3-days: post-operative

post-operative kyphotic angle, which returned to a preoperative level over the 24-month period (Table 3, Fig. 6).

\section{Adverse events}

No neurologic, embolic or cardiovascular complications were observed in any patient during or the 24 months after BKP. PMMA cement leakages were observed in 12 out of

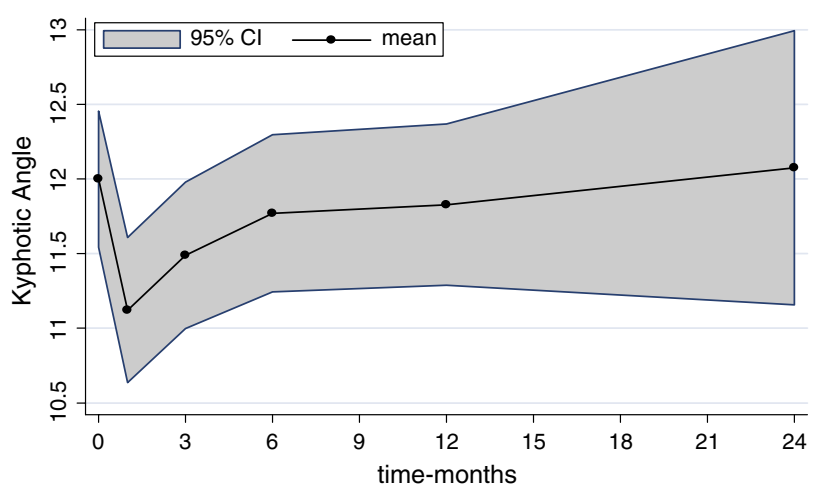

Fig. 6 Pattern of change in kyphotic angle. Time 0: pre-operative; time 3-4 days: post-operative

99 treated vertebral bodies $(12.1 \%)$. Five patients $(8 \%)$ experienced an adjacent incident fracture, three of which occurred in the first 6 months following the procedure. In two of these patients a BKP was performed again while three patients were treated conservatively.

Operative details

The procedure took on average $32 \mathrm{~min}$ for each level, the mean amount of cement application being $5.3 \mathrm{ml}$ (range 2.5-8.5) per vertebra. All patients were discharged from the hospital between the second and fourth day postprocedure.

\section{Discussion}

Patients with osteolytic lesions due to metastatic disease are subject to significant mortality and morbidity $[13,15]$. Given improved survival with contemporary oncologic treatment, effective management of pain, disability and loss of health-related quality of life is becoming increasingly important. BKP is a minimally invasive procedure 
that stabilises the vertebral fracture, that is known reduce the intensity of pain and enhance patient function and health-related quality of life of patients with painful osteoporotic VCFs [2, 12, 23]. Few studies have reported on the outcomes of BKP in the treatment of metastatic lesions of the spine.

This prospective study shows BKP to provide pain relief and improve the functional capacity of patients with painful or unstable metastatic VCFs up to 24 months following intervention. BKP was found to be a safe procedure, no patient experiencing a symptomatic cement leakage or other serious adverse event.

Our clinical efficacy findings are consistent with those of previous studies of BKP in these patients with malignant lesions. Dudeney et al. [5] reported on the treatment of vertebral fractures in multiple myeloma lesions. They performed $55 \mathrm{BKP}$ procedures in 18 patients. In concordance with our results, significant improvement were seen in average pain score (VAS) for BKP from pre- to posttreatment, as well as for the oswestry disability index $(P<0.05)$. Furthermore significant improvement in health-related quality of life (Short Form-36) scores was seen for the domains bodily pain, physical function, vitality, and social functioning. At 1-year follow-up, both pain VAS and Oswestry Disability Index increased slightly. This increase was thought by the authors to reflect disease progression. Masala et al. [16] treated 33 patients (2 patients with aggressive hemangioma, 8 patients with myeloma, and 23 patients with metastases) suffering from severe motion pain in the back with BKP and vertebroplasty. The two interventions had an equivalent impact on pain relief up to 6-month post-procedures.

A specific advantage of BKP is that it makes cement augmentation safer [2, 9, 12, 23]. In our study PMMA cement leaks were seen in $12 \%$ of treated vertebrae. This figure is comparable with the range of leakage reported by BKP studies in malignant VCFs, i.e. 0-21.8\% [23]. In contrast, systematic reviews of vertebroplasty series have reported an overall cement leak rate of some $40 \%$, ranging from of 2 to $67 \%$ [12, 23]. Fourney et al. [7] reported a direct comparison on the treatment of tumorous lesions with vertebroplasty and kyphoplasty in 56 patients undergoing 65 vertebroplasties and 32 balloon kyphoplasties. Leakage was observed in $9 \%$ of vertebroplasties and $0 \%$ of balloon kyphoplasties.

In accord with previous studies in metastatic lesions, BKP was associated with a restoration in vertebral height and kyphotic angle post-operatively and in the 3-month period following procedure $[5,7,8,11,16,20,24]$. These radiographic outcomes were seen to return to pre-operative levels at 12 months and beyond. However, unlike pain relief and enhanced function, height restoration and kyphotic correction are not the first priority in this population. That improvements in deformity were not sustained is most plausibly related to the natural history of the disease, i.e. a gradual continued increase of vertebral deformity over the disease course. Although BKP may simply serve to delay the deformity process for a 3-6-month period, importantly pain relief and improvements in function were sustained to 24 months.

Further, all patients in this study received radiation therapy and/or chemotherapy, we believe it unlikely that these therapies would have substantially contributed to the improvements in outcomes seen in this study.

\section{Conclusions}

Balloon kyphoplasty is a minimally invasive procedure that provides immediate and long-term pain relief and improvement in functional ability in selected patients with metastatic VCFs. The procedure appears to have good long-term safety.

Open Access This article is distributed under the terms of the Creative Commons Attribution Noncommercial License which permits any noncommercial use, distribution, and reproduction in any medium, provided the original author(s) and source are credited.

\section{References}

1. Borgström F, Zethraeus N, Johnell O, Lidgren L, Ponzer S, Svensson O, Abdon P, Ornstein E, Lunsjö K, Thorngren KG, Sernbo I, Rehnberg C, Jönsson B (2006) Costs and quality of life associated with osteoporosis-related fractures in Sweden. Osteoporos Int 17:637-650

2. Bouza C, López T, Magro A, Navalpotro L, Amate JM (2006) Efficacy and safety of balloon kyphoplasty in the treatment of vertebral compression fractures: a systematic review. Eur Spine J 15:1050-1067

3. Bouza C, López T, Palma M, Amate JM (2007) Hospitalised osteoporotic vertebral fractures in Spain: analysis of the national hospital discharge registry. Osteoporos Int 18:649-657

4. Cockerill W, Lunt M, Silman AJ, Cooper C, Lips P, Bhalla AK, Cannata JB, Eastell R, Felsenberg D, Gennari C, Johnell O, Kanis JA, Kiss C, Masaryk P, Naves M, Poor G, Raspe H, Reid DM, Reeve J, Stepan J, Todd C, Woolf AD, O'Neill TW (2004) Health-related quality of life and radiographic vertebral fracture. Osteoporos Int 15:113-119

5. Dudeney S, Lieberman IH, Reinhardt MK, Hussein M (2002) Kyphoplasty in the treatment of osteolytic vertebral compression fractures as a result of multiple myeloma. J Clin Oncol 20:23822387

6. Fairbank J, Pynsent P (2000) The oswestry disability index. Spine 25:2940-2953

7. Fourney DR, Schomer DF, Nader R (2003) Percutaneous vertebroplasty and kyphoplasty for painful vertebral body fractures in cancer patients. J Neurosurg 98:21E2-30E2

8. Gaitanis IN, Hadjipavlou AG, Katonis PG, Tzermiadianos MN, Pasku DS, Patwardhan AG (2005) Balloon kyphoplasty for the treatment of pathological vertebral compressive fractures. Eur Spine J 14:250-256 
9. Gill JB, Kuper M, Chin PC, Zhang Y, Schutt R Jr (2007) Comparing pain reduction following kyphoplasty and vertebroplasty for osteoporotic vertebral compression fractures. Pain Physician 10:583-590

10. Grados F, Depriester C, Cayrolle G, Hardy N, Deramond H, Fardellone P (2000) Long-term observations of vertebral osteoporotic fractures treated by percutaneous vertebroplasty. Rheumatology (Oxford) 39:1410-1414

11. Grohs JG, Krepler P (2004) Minimal-invasive stabilisierung osteoporotischer wirbelkorpereinbruche. Radiologe 44:254-259

12. Hulme PA, Krebs J, Ferguson SJ, Berlemann U (2006) Vertebroplasty and kyphoplasty: a systematic review of 69 clinical studies. Spine 31:1983-2001

13. Lad SP, Patil CG, Lad EM, Boakye M (2007) Trends in pathological vertebral fractures in the United States: 1993 to 2004. J Neurosurg Spine 7:305-310

14. Lieberman IH, Dudeney S, Reinhardt MK, Bell G (2001) Initial outcome and efficacy of kyphoplasty in the treatment of painful osteoporotic vertebral compression fractures. Spine 26:16311638

15. Lunt M, O'Neill TW, Felsenberg D, Reeve J, Kanis JA, Cooper C, Silman AJ, European prospective osteoporosis study group (2003) Characteristics of a prevalent vertebral deformity predict subsequent vertebral fracture: results from the European prospective osteoporosis study (EPOS). Bone 33:505-513

16. Masala S, Lunardi P, Fiori R, Liccardo G, Massari F, Ursone A, Simonetti G (2004) Vertebroplasty and kyphoplasty in the treatment of malignant vertebral fractures. J Chemother 16(Suppl 5):30-33
17. Masala S, Fiori R, Massari F, Simonetti G (2005) Kyphoplasty: indications, contraindications and technique. La Radiol Med 110:97-105

18. Papaioannou A, Kennedy CC, Ioannidis G, Brown JP, Pathak A, Hanley DA, Josse RG, Sebaldt RJ, Olszynski WP, Tenenhouse A, Murray TM, Petrie A, Goldsmith CH, Adachi JD (2006) Determinants of health-related quality of life in women with vertebral fractures. Osteoporos Int 17:355-363

19. Perez-Higueras A, Alvarez L, Rossi RE, Quinones D, Al-Assir I (2002) Percutaneous vertebroplasty: long-term clinical and radiological outcome. Neuroradiology 44:950-954

20. Persaud R, Bland JM, Altman DG (1994) Correlation, regression, and repeated data. BMJ 308:1510

21. Phillips FM, Ho E, Campbell-Hupp M, McNally T, Todd Wetzel F, Gupta P (2003) Early radiographic and clinical results of balloon kyphoplasty for the treatment of osteoporotic vertebral compression fractures. Spine 28:2260-2265

22. Puffer S, Torgerson DJ, Sykes D, Brown P, Cooper C (2004) Health care costs of women with symptomatic vertebral fractures. Bone 35:383-386

23. Taylor RS, Fritzell P, Taylor RJ (2007) Balloon kyphoplasty in the management of vertebral compression fractures: an updated systematic review and meta-analysis. Eur Spine J 16:1085-1100

24. Weisskopf M, Herlein S, Birnbaum K (2003) Kyphoplasty-a new minimal invasive treatment for repositioning and stabilising vertebral bodies. Zeit Orthop Inre Grenz 141:406-411 